\title{
El Concepto de Ladera Urbana
}

Elsa Lily Caballero Zeitún

\section{Resumen}

Cerrando la década de los noventa Centroamericana fue afectada drásticamente por el fenómeno hidrometeorológico Mitch, el desastre puso de manifiesto las debilidades estructurales con las que se construyeron por varias décadas los asentamientos humanos especialmente la tremenda vulnerabilidad de la población.Diferentes organismos internacionales y gobiernos nacionales han apoyado acciones para disminuir la vulnerabilidad y se ha generado un mayor conocimiento sobre amenazas y riesgos de desastre (OEA, CEPREDENAC, CEPAL, Banco Mundial, $B I D, P N U D, L A R E D)$ entre los de mayor presencia en la región.

Los avances en la temática han aclarado conceptos, generado instrumentos para la gestión y prevención del riesgo de desastre; desde el punto de vista de que los desastres no son naturales, la intervención humana es definitiva en la profundización de los efectos de las amenazas.

Esta reflexión avanza sobre la necesidad de que se incluya la gestión del riesgo como parte de la matriz de planificación urbana, y no algo externo, interesa especialmente la relación entre el emplazamiento físico y las formas de ocupación del suelo por los asentamientos humanos. Con el Concepto de Ladera Urbana, ahondamos en la especificidad de este tipo particular de asentamientos humanos, común a muchas ciudades del planeta.

Palabras Clave: laderas urbanas, planificación urbana, construcción social del hábitat gestión del riesgo.

\section{Abstract}

Closing the ninety-nineties Central America was drastically affected by the hydrometeorological phenomenon "Mitch", the disaster exposed the structural weaknesses with which the human settlements were built for decades and especially the 
extreme vulnerability of the exposed population. Different international institutions and the national government have supported actions to reduce vulnerability and generated more knowledge and awareness about disaster risks and hazards; The OAS, CEPREDENAC, CEPAL, World Bank, IDB, UNDP, LA RED are among the ones with the largest presence in the region.

The advances in the subject have clarified concepts, generated instruments for risk management and disaster prevention; this from the point of view that disasters are not natural, human intervention plays a fundamental role in deepening the effects of the hazards.

This discussion is carried upon the need to include risk management as part of the urban planning matrix, and not as something external, is of particular interest the relationship between the geophysical landscape and the layout and land use of the human settlements. With the Concept of Urban Slopes, we delve into the specificity of this particular type of city that is common to many cities on the planet.

Keywords: urban slopes, urban planning, social construction of habitat, risk management

Elsa Lily Caballero Zeitún, Doctora en Ciencias Sociales, Maestría en Gestión Social Urbana. Facultad de Ciencias Sociales UNAH 


\section{Introducción}

En la problemática urbana, la ocupación de las laderas para usos urbanos es un fenómeno fáctico, cuyo análisis generalmente se realiza después del suceso de catástrofes, grandes o pequeñas, producto de fenómenos socio-naturales o estrictamente antrópicos. Sin embargo, la literatura científica sobre la ocupación de laderas urbana es muy escasa.

Abordar conceptualmente la ladera urbana, es una necesidad que va más allá de los riesgos que enfrentan las comunidades emplazadas en este tipo de accidentes geográficos, ello no implica desconocer la problemática de los riesgos, al contrario, es un intento por comprender mejor la dinámica que se establece entre un fenómeno físico, como lo es la ladera y un fenómeno social, como lo es el proceso de ocupación del suelo.

En la teoría de la gestión del riesgo, la premisa es que, son los procesos humanos los que generan mayor o menor gravedad de los daños, las amenazas, principalmente de origen natural, interactúan en un ambiente que ha sido intervenido y construido socialmente. La calidad de las intervenciones y sobre todo si se tiene conciencia y criterios de intervención que contribuyan a minimizar las consecuencias de los fenómenos que potencialmente pueden causar daños a las personas y sus bienes de vida, serán determinantes como medidas preventivas frente a los riesgos.

El Concepto de Laderas Urbanas, apunta en esta dirección, iniciar una discusión teórica que ayude a comprender el fenómeno como tal, independientemente de los riesgos a que se esté expuesto, para lograr y mejorar criterios de planificación e intervención física urbana que consideren la especificidad de los asentamientos humanos emplazados en laderas, situación que comparten muchas ciudades del planeta.

\section{- $\quad$ El Concepto de Ladera}

La ladera es el declive de un monte, montaña o altura, cuya pendiente es el ángulo que forma con la horizontal. (Diccionario de la lengua española 2005), existen varios términos asociados al vocablo ladera: cuesta, pendiente, desnivel, declive, escarpe, vertiente, ribazo, inclinación, talud, rampa, bajada, falda.

La ladera, se define en la geografía como una de las características de la morfología de la superficie terrestre o formas del relieve y es producto de los fenómenos del ciclo geográfico. La morfo genética se da por los procesos de erosión, 
transporte y sedimentación de materiales, dándole forma a la superficie de la tierra, la que evoluciona por procesos constructivos y destructivos permanentemente afectados por la fuerza de la gravedad y los procesos geomorfológicos que modelan constantemente la superficie de la tierra y que están determinados por factores geográficos, bióticos, geológicos y los antrópicos.

Una de las ramas de la geomorfología es la de laderas, existen también la climática, fluvial, eólica, glaciar y la estructural. La ladera es parte de lo que en geología se denomina accidentes geográficos ${ }^{1}$, que consisten en unidades de relieve con propiedades morfométricas relativamente homogéneas, relativamente pequeñas de la superficie terrestre y limitadas por líneas de discontinuidad. Los tipos de accidentes identificados se han clasificado por criterios de: inclinación; fluviales; montañosos y glaciares; volcánicos y erosivos.

Entre los elementos importantes a considerar de las laderas es el tipo de materiales que la constituyen, los expertos distinguen entre substrato rocoso o roca (bedrock), derrubios (debris) y tierra (earth). Los derrubios consisten en un suelo de composición granulométrica gruesa, es decir, formado mayoritariamente por gravas y bloques y los de tierra tienen un contenido importante de finos, es decir, arenas, limos y arcillas. Se trata de la distinción entre materiales cohesivos como la tierra y no cohesivos como los derrubios, (Corominas, J. 1989. pág. 4), más el material orgánico que siempre está presentes en el suelo. Estas distinciones son importantes al momento de evaluar uno de los factores de riesgo más importantes de las laderas como lo es el movimiento de las mismas.

\section{Movimiento de Laderas}

Por su morfología más los factores climáticos, bióticos, geológicos y antrópicos, las laderas están sometidas a movimientos de diferentes magnitudes que pueden darse como subsidencias (deslizamientos o hundimientos progresivos) y colapsos (desplomes) de laderas, que pueden ser desde lentos, rápidos a extremadamente rápidos.

"Se distinguen dos fases principales en los movimientos de ladera: (a) la fase previa a la rotura, que puede ser de larga duración. En ella se producen pe-

\footnotetext{
1 Un accidente geográfico es una unidad geomorfológica, se clasifican por características tales como elevación, pendiente, orientación, estratificación, exposición de roca y tipo de suelo. Ejemplos de accidentes geográficos son los montes, acantilados, valles, etcétera. Los océanosycontinentes son los accidentes de orden máximo. Los elementos genéricos de los accidentes geográficos son los fosos, picos, canales, crestas, pasos, estanques, llanos, etcétera. (Larousse Editorial, S.L. 2007).
} 
queñas deformaciones, a menudo imperceptibles pero que pueden ser de orden métrico en los grandes deslizamientos. La superficie de separación entre la masa en movimiento y el terreno no ha llegado a desarrollarse por completo (b) la fase de rotura, por lo general caracterizada por la formación de una superficie o zona de cizalla continua en el terreno con movimientos desde muy lentos a extremadamente rápidos, hasta que se produce el reajuste de la masa deslizada y el movimiento se para. En algunas ocasiones se dan fases de reactivación, que pueden ser episódicas o continuas con variaciones estacionales de la velocidad de deformación" (Corominas, J. 1989. Pág. 6).

Los movimientos de laderas son estimulados por la acción de la gravedad al romperse el equilibrio de los materiales (rocas, derrubios, tierra) que se deslizan ladera abajo, asociados a fuerzas gravitacionales provocadas por factores internos como las propiedades del suelo, discontinuidades, inclinación y altura, y los factores externos, las lluvias intensas y prolongadas, los sismos, la actividad volcánica, la erosión y el hombre (Mendoza López, Manuel J. y Domínguez, Morales Leobardo, 2002).

Los movimientos de laderas son clasificados según sus mecanismos de movimiento, de acuerdo a la literatura consultada son cinco los mecanismos principales: caídas, vuelcos, deslizamientos, expansiones laterales y flujos. Según Jordi Corominas (1989), existen los llamados movimientos complejos y las deformaciones sin rotura manifiesta o previa a la rotura, con muchas variantes identificadas. En la inestabilidad influyen condicionantes de inclinación; tipo de materiales (substrato rocoso, materiales cohesivos y materiales no cohesivos); tensión y resistencia del material y la humedad o contenido de agua que aumentan o disminuyen el volumen según el tipo de materiales, etc., y que condicionan el tipo e intensidad del movimiento (Corominas, J. 1989).

"Los parámetros que influyen en la inestabilidad del suelo se relacionan con el agua, el material, la geometría del terreno, y las situaciones del ambiente (fuerzas, procesos, etc.). Los parámetros son: tipo de material: roca, capa alterada y cobertura; pendiente: gradiente, forma y longitud; condiciones hidrológicas: infiltración, permeabilidad, NAF, cantidad de agua; procesos morfológicos: erosión fluvial e hídrica, movimientos masales y parámetros externos: distribución de la pluviosidad, es decir, relación (intensidad/período), sismicidad, vulcanismo" (Duque Escobar, Gonzalo. 2000).

Los riesgos de subsidencias (deslizamientos o hundimientos progresivos) y colapsos o desplomes de laderas se incrementan en condiciones de pendientes 
mayores al 15 o 20\%; en las épocas de lluvia con el aumento de las escorrentías; el estancamiento de aguas (lluvias, servidas o cloacales); los cambios en el nivel freático; la alteración de estratos y materiales; presencia de zonas de cizalla, zonas de falla y fallas ${ }^{2}$ o fracturas y los planos de estratificación paralelos a la pendiente.

A la naturaleza intrínseca de las laderas que por sus componentes y características están sujetas a movimientos de diferentes intensidades, se le agregan los factores externos clasificados en dos grandes categorías y que pertenecen a la clasificación de factores de riesgo externo: los naturales (climáticos, sismos, erupciones volcánicas) y los antrópicos.

Entre los factores antrópicos desestabilizadores de laderas tenemos: las excavaciones, la construcción, los rellenos de hondonadas, las explosiones, el socavamiento de la base de la ladera, construcción o desestabilización de taludes, la desviación de causes de cuerpos de agua en la base de la pendiente, la sobre explotación hídrica, extracción de material del lecho de ríos y quebradas y erosión por deforestación.

"Una de las clasificaciones más utilizadas para distinguir los movimientos de ladera es la Clasificación de Varnes, que distingue los siguientes tipos: derrumbes o caídas, basculamiento, arrastre, deslizamientos, y flujos o coladas. De estos los más comunes en Honduras son los derrumbes o caídas, los deslizamientos y los flujos o coladas" (COPECO/Cooperación Suiza en Centro América/ PNUD. SF).

Bajo estas consideraciones, podemos definir que una ladera es un accidente geográfico de declive, susceptible de presentar movimientos de subsidencia o colapso por la incidencia y combinación de factores internos y externos.

\section{El Concepto de Ladera Urbana}

La construcción del concepto de ladera urbana responde a una necesidad práctica en el propósito de coadyuvar en la búsqueda de alternativas a la forma de ocupación del suelo urbano y así minimizar los riesgos de pérdidas humanas y de

\footnotetext{
${ }^{2}$ Existen tres conceptos fundamentales relacionados entre sí: falla, zona de falla y zona de cizalla (e.g., McClay, 1987; Davis y Reynolds, 1996), utilizados a veces de manera indistinta y de manera incorrecta. Una falla es por definición una fractura frágil a lo largo de la cual ha ocurrido un desplazamiento visible, en general paralelo a la superficie de la misma. Por su parte una zona de falla se encuentra compuesta por innumerables superficies de falla frágiles, subparalelas e interconectadas, estrechamente espaciadas conteniendo zonas de brecha o faultgouge. La zona de cizalla corresponde a una ancha zona de deformación generada bajo condiciones dúctiles a dúctiles-frágiles"Oyarzun, Roberto y Doblas, Miguel (sf).
} 
bienes de vida en los emplazamientos de asentamientos humanos sobre terrenos escarpados. Para nuestro propósito conceptualizamos la ladera urbana como:

Ladera Urbana, la forma de ocupación del suelo sobre un accidente geográfico o una cadena de accidentes geográficos con declives de alta o mediana pendiente (entre los $45^{\circ}$ y $30^{\circ}$ ), con un uso intensivo en vivienda, equipamiento urbano e infraestructura económica y social, susceptible de presentar movimientos de subsidencia o colapso por la incidencia y combinación de factores internos y externos, que constituyen un riesgo de desastre para sus ocupantes y sus bienes de vida.

Bajo este concepto, la ladera urbana es el producto de las prácticas humanas en cuanto al uso y forma de ocupación de superficies terrestres inclinadas donde se emplazan los asentamientos humanos.

La literatura y la investigación especializada se ha concentrado preferentemente en el uso agrícola de las laderas, por lo generalizado de las prácticas ya sea de deterioro o de conservación, sin embargo, el uso urbano de las laderas también es generalizado, son muchas las ciudades 0 asentamientos humanos asentados en terrenos de topografía escarpada. El tema de las laderas urbanas no podemos analizarlo desde la práctica de conservación de suelos como lo sería el caso de las laderas de uso agrícola, las de uso urbano debemos analizarlas desde la noción de espacio socialmente construido.

Las ciudades no siempre se erigen sobre superficies planas, muchas han sido fundadas o se han expandido sobre superficies inclinadas, esta forma de ocupación de las laderas no ha sido objeto de una conceptualización que discuta sobre la dinámica que se establece entre la morfogenética y el uso urbano de las laderas, lo que se registra y analiza principalmente es la subsidencia o colapso para evaluar los daños.

En la imagen 1 se observa como una ciudad emplazada en un valle, al pasar por procesos de crecimiento urbano, progresivamente se pasa a ocupar las áreas inclinadas. La ciudad de San Pedro Sula, Honduras, (15³0'29.47" N $88^{\circ} 01^{\prime} 32.16^{\prime \prime}$ ) está ubicada en la porción oeste del Valle de Sula. La topografía es plana con una altitud en el valle entre 40 a $100 \mathrm{msnm}$, con una ligera inclinación hacia el este, al oeste limita con la Montaña del Merendón, sobre la parte nor-oeste de la ciudad se ha dado la expansión urbana alcanzando cotas hasta los 350 msnm. 


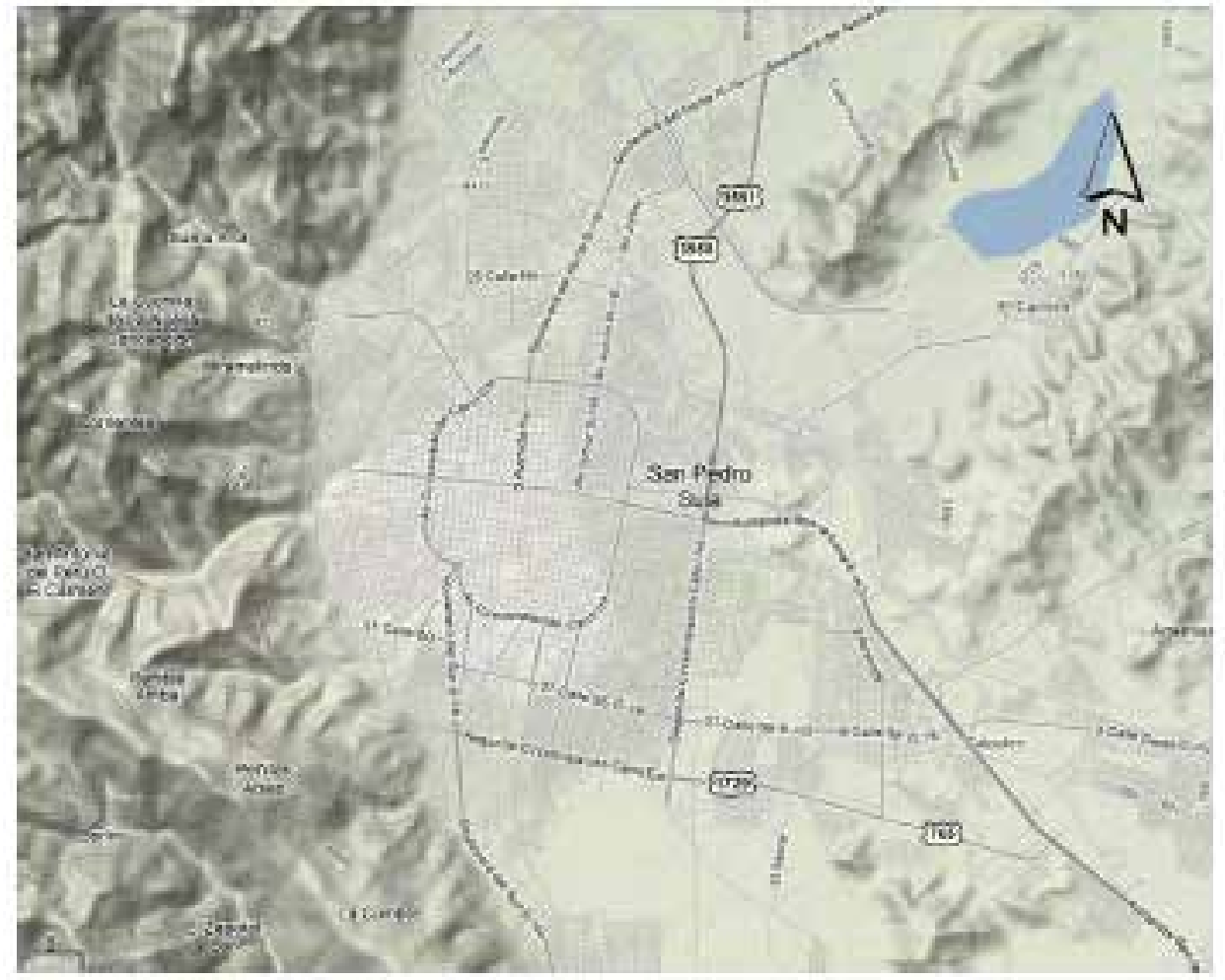

Fuente: Imagen Google Maps, 2010.

"En las ciudades, y sobre todo en las zonas de ladera, las condiciones geomorfológicas se caracterizan por ser un foco visual importante, debido a su forma particular urbana y su paisaje natural, pero, con un desarrollo en la urbanización que no ha hecho en gran parte un estudio físico del lugar y ha establecido una forma urbana no apta a las características físicas del lugar, en especial la topografía" López, John Jairo; López Carlos Andrés, 2004).

Las laderas urbanas son un fenómeno fáctico sobre el cual no hay un desarrollo teórico que explique la dinámica entre el atributo físico (ladera) y el proceso social (la ocupación), algunos de los criterios considerados son:

- En el momento de la ocupación, por lo general, el criterio principal es la optimización del suelo para la lotificación, ya sea esta formal o informal, procurando hacer el mejor uso del suelo para ubicar las edificaciones y en el caso de 
urbanizaciones formales se incluye la mejor ubicación de redes de servicios. Las urbanizaciones informales solo se ocupan de la ubicación de las edificaciones para uso habitacional y algunas cuantas calles de acceso.

- En algunos casos, se considera el criterio paisajístico, con el cual se tiende a respetar la morfología del terreno.

- La ocupación urbana de áreas escarpadas se considera como un fenómeno a estudiar hasta el momento en que suceden desastres de origen antrópico o socio-natural o por la ubicación de familias y edificaciones en áreas catalogadas como zonas de riesgo.

- Otra forma de conceptualización (que no es exclusiva a las laderas) es el concepto de suelo bien ubicado y bien servido, que hace referencia a la localización del sitio en tanto espacio físico y equipamiento urbano.

En el caso que nos ocupa, la conceptualización de ladera urbana,son útiles los conceptos de zona de riesgo y suelo bien ubicado y bien servido,al referir a la calidad del suelo para uso humano (vivienda, centros de trabajo, vías de acceso, etc.). Con el de zonas de riesgo, se hace referencia al problema social de ubicación de una parte de la población urbana, principalmente pobre, que se ve obligada a ocupar zonas expuestas a factores de riesgo y el concepto de suelo bien servido y bien ubicado, se refiere a la ubicación de la población respecto de las fuentes de trabajo y equipamiento de la ciudad, lo que Martín Smolka (1981) define como ventajas locacionales de un terreno.

Para los pobres de la ciudad, generalmente localizados en zonas de riesgo, significa, la ocupación de suelos mal ubicados y mal servidos, que en efecto, constituyen uno de los problemas más agudos de la actualidad de las ciudades de los países de América Latina.

No obstante la importancia de estos dos conceptos, por separado no terminan de conceptualizar el problema, con el concepto de laderas urbanas se pretende relevar que: una buena parte de la población, si no toda, está asentada sobre un accidente geográfico o una cadena de accidentes geográficos con declives susceptibles de presentar movimientos de subsidencia o colapso por la incidencia y combinación de factores internos y externos, el fenómeno no sólo está determinado por la situación socioeconómica, igualmente lo está por la geomorfología de la superficie del territorio ocupado por los asentamientos humanos. 
Son muchos los procesos que determinan la categoría espacio socialmente construido, sin embargo, para nuestro propósito consideramos que uno de los elementos más representativos y síntesis de la dinámica e interacción entre la acción humana y la morfología del territorio, es el trazo o trama urbana de la ladera. Sobre la traza se da la ubicación de las edificaciones y las adaptaciones tecnológicas de acuerdo a las condiciones del sitio de emplazamiento y la situación socioeconómica de los ocupantes.

Centrar el análisis en la traza o trama urbana, tiene sentido en tanto es la expresión física de una forma particular de ocupación del suelo, sintetiza la forma física con la forma de ocupación. Con la traza se identifica la morfología, el diseño, la disposición interna, la distribución de un espacio físico por medio de figuras geométricas regulares o irregulares que hacen referencia a elementos como calles, callejones, pasadizos, esquinas, redondeles, áreas construidas, no construidas, etc. (polígonos, líneas y puntos), pero también hace referencia a la huella o vestigio que deja la acción humana sobre el territorio. En ese sentido la traza urbana es uno de los elementos del espacio socialmente construido sobre la topografía escarpada del terreno y que conforma la estructura urbana.

Las formas tipológicas de la trama urbana son la ortogonal y la orgánica, la primera, conocida como trazado hipodámico o tablero de Pizarro, el diseño de las calles son rectilíneas cruzadas en ángulo recto, formando manzanas o cuadras rectangulares. La segunda, con la cual se identifica a las ciudades medioevales y musulmanas, sus formas son variadas (según la historia y sitio donde se emplaza la ciudad), el trazo orgánico puede ser planificado o no planificado y siempre guarda una relación con la forma del medio físico donde se emplaza la ciudad.

A partir de estos dos tipos se construyen derivaciones como la traza reticular una derivación de la ortogonal que en su forma se asemeja a una red y la irregular derivada de la orgánica (Imagen 2), que no tiene un patrón urbanístico definido y se adapta a la topografía del terreno. Esta tipología se puede observar en terrenos planos y escarpados ya que se corresponden a los patrones de ocupación del suelo. 
Imagen 2: Tipología Trazos Urbanos de Ciudades en Planicie, el caso de la Ciudad de Comayagua, Honduras.



Fuente: Imágenes Google Earth, 2005. Ciudad de Comayagua. 
En las ciudades emplazadas en laderas se pueden observar los cuatro tipos de traza, pero el paisaje principal es de ladera y no de planicie. Donde la topografía lo permite se observa la traza ortogonal generalmente sobre pequeñas mesetas, sin embargo, por lo escarpado del terreno las más comunes son la traza irregular, la reticular y la orgánica, planificadas y no planificadas.

\section{La Traza Irregular en Laderas}

El criterio urbanístico es el personal. Las edificaciones se construyen según criterios personales de los ocupantes del suelo, en algunos casos por relaciones familiares, étnicas o por afinidad de origen y en otras, por simple agregación al momento de la ocupación, donde no necesariamente se considera la topografía, vialidad y disposición de servicios urbanos, la accesibilidad no es proyectada en relación a la disposición de las edificaciones, generalmente son las edificaciones las que le dan forma a los accesos. La experiencia de los asentamientos irregulares de América Latina son los mejores ejemplos de este tipo de emplazamientos.

Acerca del fenómeno de la informalidad y precariedad urbana, hoy calificado como Urbanismo Popular, es definido como la producción de una parte importante de la ciudad a partir de la producción social del hábitat y la autoconstrucción de vivienda y gestión de servicios básicos, que se caracteriza por el aprovechamiento máximo del suelo para uso habitacional; tienden a ubicarse en la periferia de la ciudad; constituye un factor decisivo en la expansión del área urbanizada; la superficie ocupada es mayor que la del suelo regularizado y mayor densidad constructiva y poblacional (Duhau, Emilio; Giglia, Ángela, 2008).

En la región, los asentamientos irregulares emplazados en laderas por lo general no cuentan con las obras de infraestructura adecuada para la estabilidad de taludes y el manejo de las aguas lluvias y servidas, no han sido construidos con un proceso previo de planificación y diseño urbanístico formal.

Esta es una de las características más distintivas de los asentamientos informales que se desarrollan sin ninguna planificación, más que la oportunidad y necesidad de ocupar un lote para uso habitacional y/o de trabajo, fenómeno urbano que en las ciudades latinoamericanas ha llegado a conformar la mitad o más del perímetro urbanizado. 
Imagen 3: Traza Irregular en Laderas



Fuente: Imagen Google Earth, 2002, Ciudad de Tegucigalpa, Honduras. Pendientes entre $15^{\circ}$ y $45^{\circ}$

\section{La Traza Reticular en Laderas}

Criterio urbanístico de eficiencia en el uso del suelo, esta se deriva de la noción de la forma perfecta de calles rectilíneas equidistantes cruzadas en ángulo recto (ortogonal), esta forma reticular sigue el mismo principio de ordenar el espacio en líneas y ángulos (calles y esquinas) pero en forma de red, los tamaños de manzanas y longitud de calles poseen mayor variabilidad dependiendo de las características del territorio y la densidad constructiva que se proyecta.

Los urbanizadores o autoridades locales, diseñan un trazo que intenta aproximarse lo más posible al diseño reticular generalmente con el criterio de hacer un uso eficiente del espacio disponible respecto de la inversión en edificaciones, la disposición de las vialidades y servicios básicos. Esta es una de las características más generalizadas que se ha desarrollado con los proyectos de urbanización pública y privada, con un claro criterio de maximizar la rentabilidad de la inversión. 
En los emplazamientos en laderas, la forma que adquiere la traza reticular dependerá de la disponibilidad de áreas en las cimas, pendientes u hondonadas cuya superficie permita proyectar la disposición de los elementos con patrones reticulares.

\section{Imagen 4: Traza Reticular en Laderas}

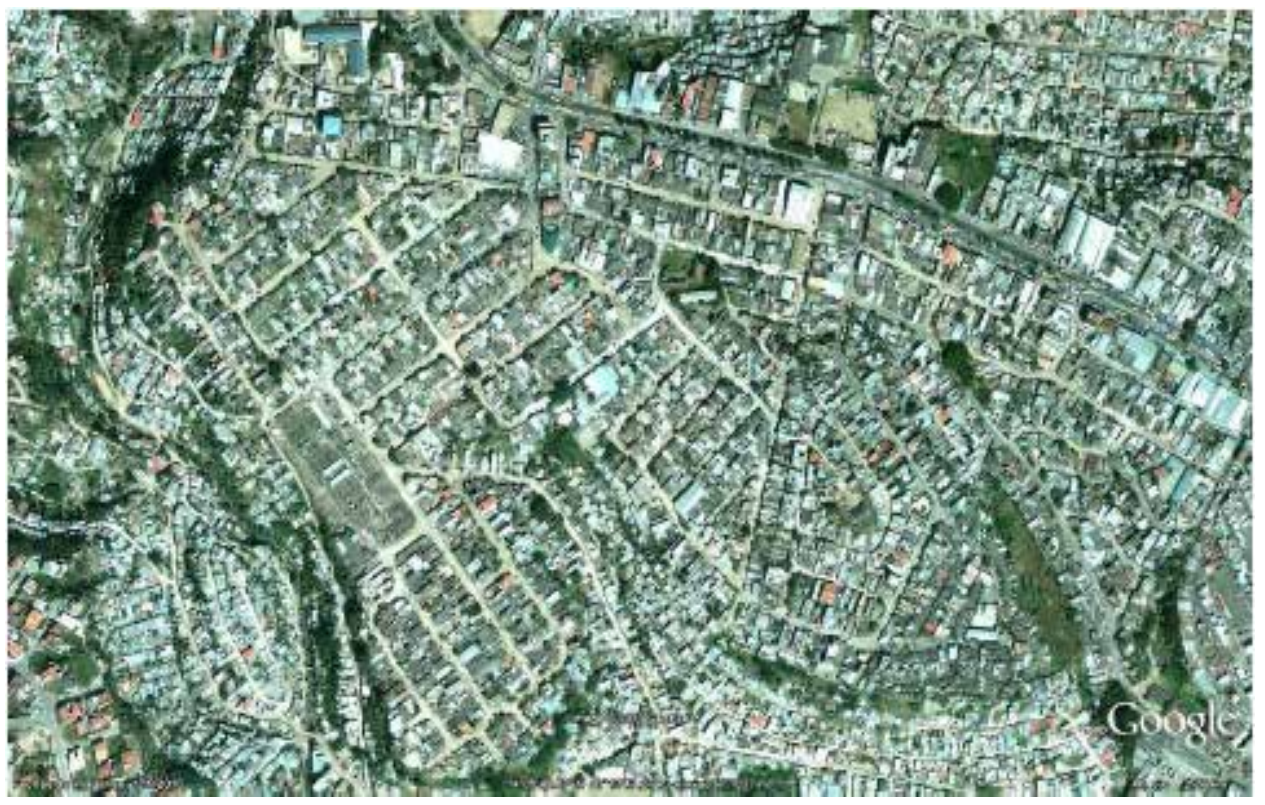

Fuente: Imagen Google Earth, 2002, Ciudad de Tegucigalpa, Honduras.

Sobre la rivera del río, con zonas de terreno plano y laderas de alta pendiente $20^{\circ}$ a $45^{\circ}$.

\section{La Traza Orgánica en Laderas}

El criterio urbanístico puede ser el personal o el de adaptación al medio físico. En consecuencia con las características del territorio las edificaciones y redes se construyen respetando los accidentes geográficos y se tiene como principio técnico respetar las curvas de nivel.

Asentamientos humanos que han construido el espacio con las adaptaciones tecnológicas de acuerdo a las condiciones del sitio de emplazamiento, especialmente en lo que a vialidad y redes de servicios se refiere con una adecuada integración a la estructura urbana en términos de accesibilidad y conectividad. 
Estos son los asentamientos emplazados en laderas que cuentan con las obras de infraestructura adecuadas, que aseguran la estabilidad de los taludes y el manejo de las aguas lluvias y servidas y, responden a un proceso previo de planificación y diseño.

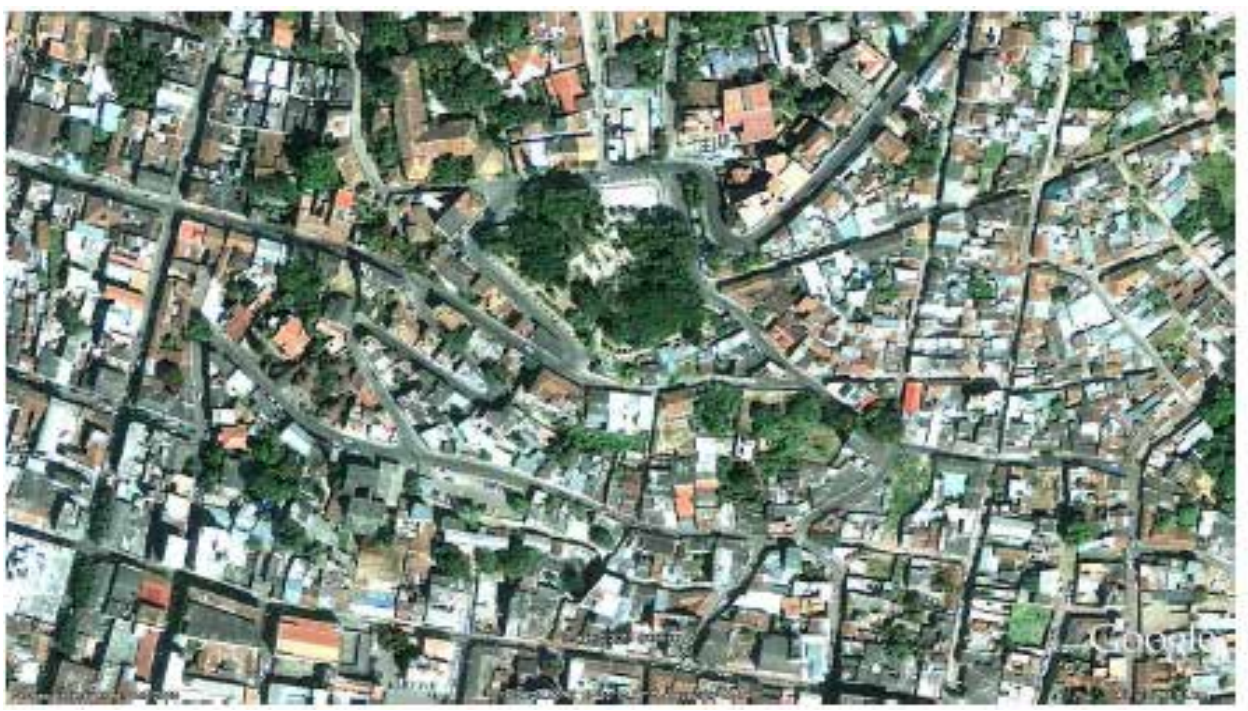

Fuente: Imagen Google Earth, 2002, Ciudad de Tegucigalpa, Honduras. Ladera de alta pendiente, la cima está a $1020 \mathrm{~m}$ y el pie de la ladera a $957 \mathrm{~m}$, con pendientes entre los $30^{\circ}$ y $45^{\circ}$

Sobre la base de esta tipología de trazo urbano, en tanto síntesis y expresión de la dinámica entre forma física y ocupación del suelo como proceso social, es posible identificar patrones urbanos que combinan diferentes categorías que le dan sentido conceptual a la ladera urbana.

Entre las categorías de mayor relevancia para analizar los patrones de ocupación del suelo urbano en zonas de laderas expresadas en la traza urbana, consideramos las de mayor relevancia el riesgo y suelos bien o mal servido y ubicado.

Las combinaciones pueden ser muy variadas y complejas según el nivel de detalle escala y territorio, para describir patrones de mayor estandarización de la ocupación urbana en laderas, tomando como ejemplo la ciudad de Tegucigalpa tenemos la siguiente clasificación: zona residencial bien ubicada y bien servida; zona 
centro, uso mixto, bien ubicado y bien servido; barrios irregulares, bien ubicados y mal servidos y, barrios irregulares, mal ubicados y mal servidos.

\section{Zona residencial bien ubicada y bien servida}

Con un trazo orgánico planificado. Derrumbes por desestabilización de laderas por malas prácticas y escorrentías. Distancia al centro de la ciudad 3 a $4 \mathrm{Km}$. Elevación entre 980 y $1069 \mathrm{msnm}$. Ladera de alta pendiente entre los $30^{\circ}$ y $45^{\circ}$.



Imagen 6: Zona residencial bien ubicada y bien servida

Fuente: Imágenes Google Earth, 2010, Ciudad de Tegucigalpa, Honduras.

Pendientes entre $45^{\circ}$ y $30^{\circ}$.

- Zona centro, uso mixto, bien ubicado y bien servido

Primer emplazamiento de la ciudad, con trazo ortogonal, reticular y orgánico planificado. Con riesgo de inundación y deslizamientos. Elevación alrededor de los $900 \mathrm{msnm}$. Terreno plano ligeramente inclinado. (pendientes entre $5^{\circ}$ y $25^{\circ}$ ). 


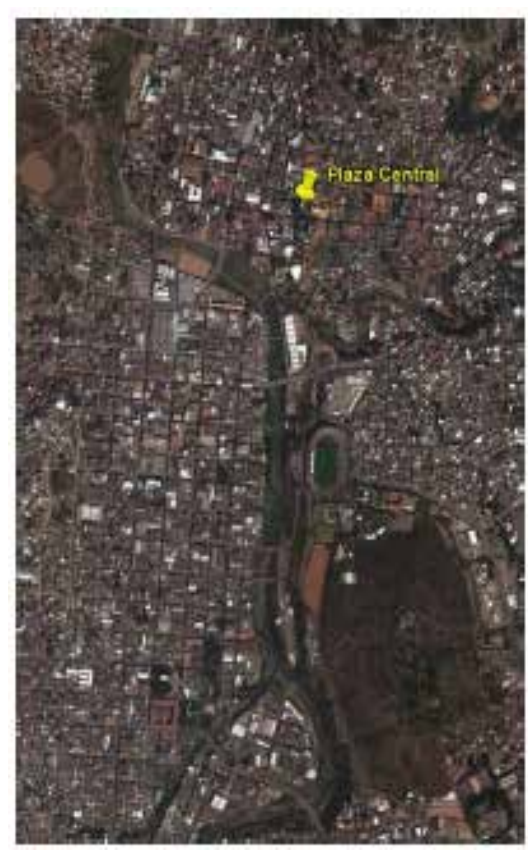

Imagen 7: Zona centro, uso mixto, bien ubicado y bien servido.

Fuente: Imagen Google Earth, 2010, Ciudad de Tegucigalpa, Honduras.

- Barrios irregulares, bien ubicados y mal servidos

Con un trazo reticular, riesgo de inundación y deslizamientos. Distancia al centro de la ciudad $4.20 \mathrm{Km}$. Elevación entre 950 a $970 \mathrm{msnm}$. Terreno plano sobre la rivera de un río. 

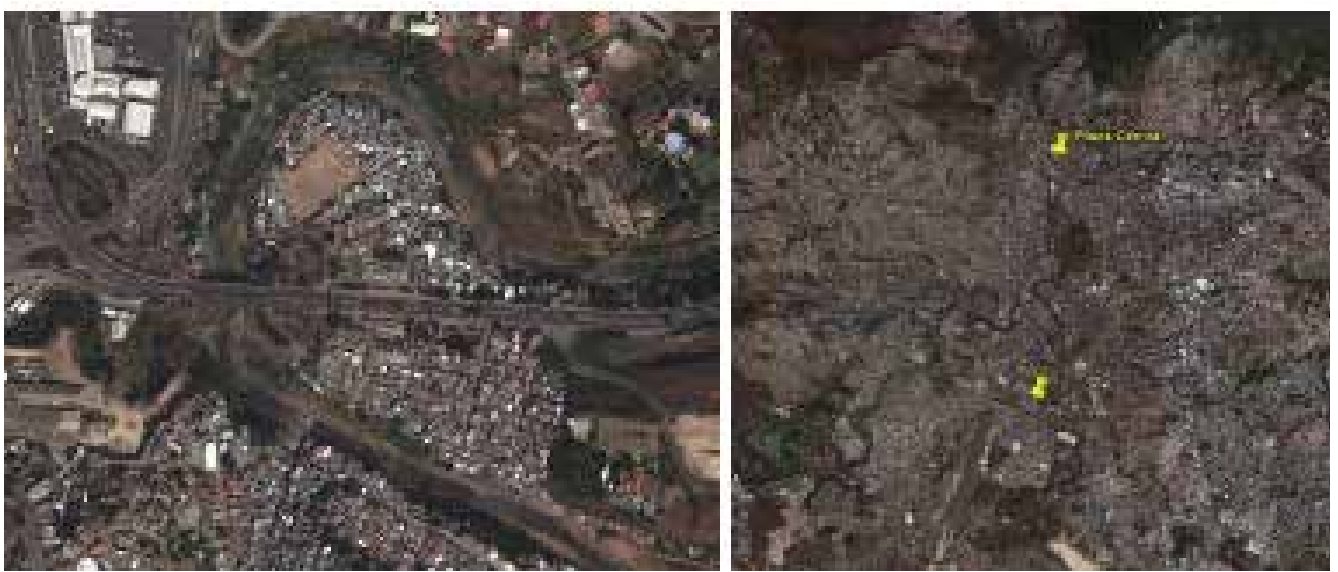

Imagen 8: Barrios irregulares, bien ubicados y mal servidos

Fuente: Imágenes Google Earth, 2010, Ciudad de Tegucigalpa, Honduras.

\section{- Barrios irregulares, mal ubicados y mal servidos}

Con trazo irregular no planificado, ubicado en zona de falla, riesgo de derrumbes y deslizamientos por escorrentías. Distancia del centro $11.25 \mathrm{Km}$. Elevación entre 1260 a $1325 \mathrm{msnm}$. Ladera de alta pendiente entre los $35^{\circ}$ y $45^{\circ}$.

Imagen 9: Barrios irregulares, mal ubicados y mal servidos


Fuente: Imágenes Google Earth, 2010, Ciudad de Tegucigalpa, Honduras, pendientes de $45^{\circ}$. 


\section{Conclusiones}

Sobre el concepto de ladera urbana ilustrando, las relaciones entre: trazo urbano-riesgo-suelo bien/mal servido y ubicado - accidentes geográficos de

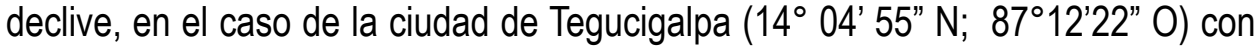
un aproximado de población de millón y medio de habitantes, es una ciudad emplazada entre un sistema de laderas, y pequeñas mesetas, con elevaciones entre los 935 a $1463 \mathrm{msnm}$ y pendientes ocupadas entre los $5^{\circ}$ y $45^{\circ}$; el área urbanizada es aproximadamente de $201 \mathrm{Km}^{2}$.En la ciudad se identifican todos los tipos de trazado urbano; más de la mitad de los asentamientos son irregulares; con riesgos de derrumbes y deslizamientos por escorrentías, "por una combinación de fenómenos hídricos y los tipos de suelos de origen volcánico, asentada sobre fallas y riesgos geológicos de derrumbe y erosión de suelos" (ING, 1990), constituyendo un riesgo de desastre para sus ocupantes y sus bienes de vida.

"Debido a la preocupación existente, distintos organismos han ejecutado estudios de amenazas en las laderas. En estos estudios se identifican los siguientes tipos de amenazas: erosión superficial, como movimientos en masa, derrumbes, deslizamientos; y erosión fluvial, es decir, flujos de lodos y escombros e inundaciones. Si bien estos fenómenos se originan en las laderas, las principales áreas de afectación estarían en la parte baja y más consolidada de la ciudad" (Fernández, María Augusta 1996).

Todas las ciudades tienen una historia geológica y ubicación específica, de acuerdo a estas características, la exposición a amenazas variará según el emplazamiento, y el riesgo de desastre dependerá de los procesos de ocupación del suelo urbano dado que no es posible ubicar un territorio que esté exento de amenazas naturales.

En cuanto a las laderas urbanas, en todo el planeta el paisaje lo constituyen sistemas montañosos y valles, en América los sistemas montañosos principales son las Rocallosas de Norteamérica, las Sierras Madres mexicanas, las montañas centroamericanas, las Antillanas y los Andes Sudamericanos, donde, a lo largo de la historia incluyendo la precolombina, las laderas han sido ocupadas por grandes, medianas y pequeñas ciudades.

"Es necesario, entonces, reconocer y entender los sistemas naturales para la construcción del hábitat humano, pero cuando los poblaciones se extienden sin criterios de sostenibilidad, los vínculos con estos sistemas se vuelven cada vez más precarios, los recursos empiezan a ser disminuidos y se vuelven El Concepto 
de Ladera Urbana insuficientes para la gran cantidad de residentes concentrados en su territorio; es aquí donde las relaciones entre el medio urbano y los procesos naturales del medio ambiente se ven notoriamente perturbados, hallando en la planificación urbana un instrumento para mejorar dicha relaciones" (López, John Jairo; López, Carlos Andrés, 2004).

La planificación urbana al incorporar la gestión del riesgo asume el uso de instrumentos de planificación e intervención física definidos a partir de los atributos del suelo en que se emplazan los asentamientos humanos, por lo que éstos deben ser adaptados a ciudades en planicies o como en el caso que nos ocupa y para una gran cantidad de ciudades, incorporar el concepto de ladera urbana, mismo que ayudará en la especificación de normativa, criterios técnicos constructivos, criterios técnicos de trazado de calles y disposición de redes de servicios urbanos así como de equipamiento social.

\section{Bibliografía}

- Corominas, J. 1989. Clasificación y Reconocimiento de los Movimientos de Ladera. En: J. Corominas (Ed.). Estabilidad de Taludes y Laderas Naturales. Monografía n³. Sociedad Española de Geomorfología. Zaragoza.http://es.scribd. com/doc/50417494/ClasificacionDeslizamientos. (Fecha de consulta.Mayo, 2011).

- COPECO/Cooperación Suiza en Centro América/PNUD. (SF)Manual para la Evaluación de Riesgo del Emplazamiento y del Medio Construido para Edificios, Viviendas y Lotificaciones. Tegucigalpa, Honduras. (Documento impreso)

- Duhau, Emilio; Giglia, Ángela, 2008. Las Reglas del Desorden: Habitar la Metrópoli, Primera Edición, Siglo XXI. Editores; Universidad Autónoma Metropolitana, Unidad Azcapotzalco. México DF.

- Duque Escobar, Gonzalo 2000. Riesgo en la Zona Andina Tropical por Laderas Inestables, Universidad Nacional de Colombia, Manizales, Colombia.

- Fernández, Aaría Augusta (Compiladora), 1996.Ciudades en Riesgo Degradación Ambiental, Riesgos Urbanos y Desastres. Red de Estudios Sociales en Prevención de Desastres en América Latina.http://www.desenredando.org/ public/libros/1996/cer/CER_cap09-ODL_ene-7-2003.pdf(Fecha de consulta. Mayo, 2011). 
- Ggeografía Física y Humana de América Latina,Registro № 188.540.

- http://www.profesorenlinea.cl/geografiagral/U200_4MHyGeog.htm. (Fecha de consulta. Mayo, 2011)

- Instituto Geográfico Nacional (IGN), 1990. Mapa Geológico de Honduras, Tegucigalpa, 2758 II G, Escala: 1:50.000.

- Larousse Editorial, S.L. 2005 Y 2007.Diccionario Manual de la Lengua Española.

- López, John Jairo; López Carlos Andrés, 2004.El Urbanismo de Ladera: un Reto Ambiental, Tecnológico y del Ordenamiento Territorial. Revista Vitácora Urbano Territorial. Enero - Diciembre, año/vol. 1, No. 008. Universidad Nacional de Colombia, Bogotá, Colombia. http://facartes.unal.edu.co/portal/publicaciones/bitacoraut/8/pregrado/b8_urbanismo_ladera.pdf. (Fecha de consulta. Mayo, 2011)

- Mendoza López, Manuel J. y Domínguez, Morales Leobardo. 2002.Estimación de la Amenaza y el Riesgo de Deslizamientos en Laderas.

- http://www.atlasnacionalderiesgos.gob.mx/index.php?option=com_docman\&task=doc_details\&gid=29\&ltemid=215. (Fecha de consulta. Mayo, 2011)

- Oyarzun, Roberto y Doblas, Miguel (SF).Fallas y Zonas de Cizalla (Parte I): Aspectos Generales. Departamento de Cristalografía y Mineralogía, Facultad de Ciencias Geológicas, Universidad Complutense, Madrid, España. Departamento de Geología, Museo Nacional de Ciencias Naturales, Consejo Superior de Investigaciones Cientificas (CSIC), España.http://www.uclm.es/users/higueras/ yymm/fallas/FallasPrimeraParte.htm (Fecha de consulta. Mayo, 2011).

- Smolka, Martín. 1982. Precio de la tierra y valorización inmobiliaria urbana: esbozo para una conceptualización del problema. Revista Interamericana de Planificación (SIAP). Volumen XV, No. 60 